\title{
Wear of dual-mobility cups: a review article
}

\author{
Anna Di Laura ${ }^{1,2} \cdot$ Harry Hothi $^{1,2} \cdot$ Clement Battisti $^{1,2}$ - Arianna Cerquiglini ${ }^{1,2}$. \\ Johann Henckel $^{1,2}$ • John Skinner ${ }^{1,2}$ - Alister Hart ${ }^{1,2}$
}

Received: 6 July 2016 / Accepted: 17 October 2016 / Published online: 9 December 2016

(C) The Author(s) 2016. This article is published with open access at Springerlink.com

\begin{abstract}
Dual-mobility (DM) cups have been clinically used in hip surgery in Europe for more than 35 years and continue to gain popularity worldwide due to promising results at reducing instability. Concerns related to polyethylene wear apply as in conventional standard bearings but are accentuated by the larger-diameter articulations with multiple surfaces. We critically reviewed the reported literature regarding the in vivo and in vitro wear occurring on all surfaces involved. We looked for patterns to create a rational classification of sites of wear and to identify areas for future research. Wear was a significant problem for first-generation designs and appeared to be design related. Improved polyethylene, thinner and smoother trunnions, chamfered rims and eccentric configuration of insert and shell seem to enhance outcome performance; however, long-term clinical evidence and retrieval studies are needed to better understand the balance of benefit and risk when opting for DM bearings.
\end{abstract}

Keywords Hip arthroplasty · Dual mobility cups $\cdot$ Wear . Bearings $\cdot$ Modularity

\section{Introduction}

The rationale for a dual-mobility (DM) hip articulation is to reduce the risk of dislocation, which continues to be one of

Anna Di Laura

anna.laura.14@ucl.ac.uk

1 Institute of Orthopaedics and Musculoskeletal Science, University College London, London, UK

2 The Royal National Orthopaedic Hospital, Stanmore, UK the leading causes of early revision in hip arthroplasty. The reported incidence of dislocation is between 0.2 and $3 \%$ during the first year following the primary procedure, up to $7 \%$ after 25 years and as high as $25 \%$ after revision arthroplasty [1, 2]. The Swedish Hip Arthroplasty Register and the National UK Joint Register report dislocation as the first reason for revision within two years after implantation $[3,4]$. The National Joint Replacement Registry of the Australian Orthopaedic Association lists dislocation following revision as the most common reason for a second revision hip replacement $(31.1 \%)$ [5]. It has been estimated that the cost of one or more reductions followed by revision surgery is $148 \%$ of the cost of a primary total hip arthroplasty (THA) [6].

With DM bearings, concerns related to polyethylene (PE) wear apply as in conventional standard bearings. However, they are accentuated due to larger diameter articulations with multiple surfaces. Additionally, wear can be severe enough to cause a decrease in retention power of the poly liner, with consequent femoral-head. Such complication was widely reported with the first-generation of DM bearings $[7,8]$ but notably reduced - up to $0 \%$-with newer-generation designs and adoption of smoother and thinner necks [9-12]. Moreover, the advent of highly cross-linked PE (HXLPE) seems to have improved this issue, as both in vitro tests [13, 14] and early clinical data have shown encouraging results in comparison with conventional PE [15-17].

The use of DM bearings has recently increase in the United States, where a large manufacturer supplies $25 \%$ of its bearings as DM. Whilst clinical studies highlight the efficacy of the design in reducing dislocation rates, wear has become a recent and controversial issue for DM bearings, and there is limited long-term follow-up data. In this study, we aimed to summarise the reported literature regarding in vivo and in vitro wear occurring on all surfaces involved in DM design, 
look for patterns to delineate a classification of sites of wear and identify areas for future research.

First, we summarise design types and evolution steps relevant to wear. Secondly, we describe the biomechanical function of DM bearings. Thirdly, we present our classification system designed to help describe wear of DM bearings. Lastly, we critique the methods used to assess PE wear.

\section{Design types and evolution relevant to wear}

DM design consists of a femoral head component captive and mobile within a PE liner, with coverage larger than a hemisphere, which in turn articulates with the acetabular shell. Therefore, there are two distinct articulations: a small articulation between the head and the PE liner, and a large articulation between the PE liner and the metal acetabular shell. Wear can occur at a minimum of three interfaces: two bearing (if metal liner between poly liner and metal shell is absent) and the taper junction (Fig. 1).

Wear can occur between the neck and poly liner as well as between the neck and the shell: the large articulation takes over from the small only when the neck of the stem comes into contact with the inlay (Fig. 2) during movements when a large range of motion $(\mathrm{ROM})$ is required - e.g. while climbing stairs [18]. The large PE liner captures a small-diameter head and functions as a large-diameter head, which increases the

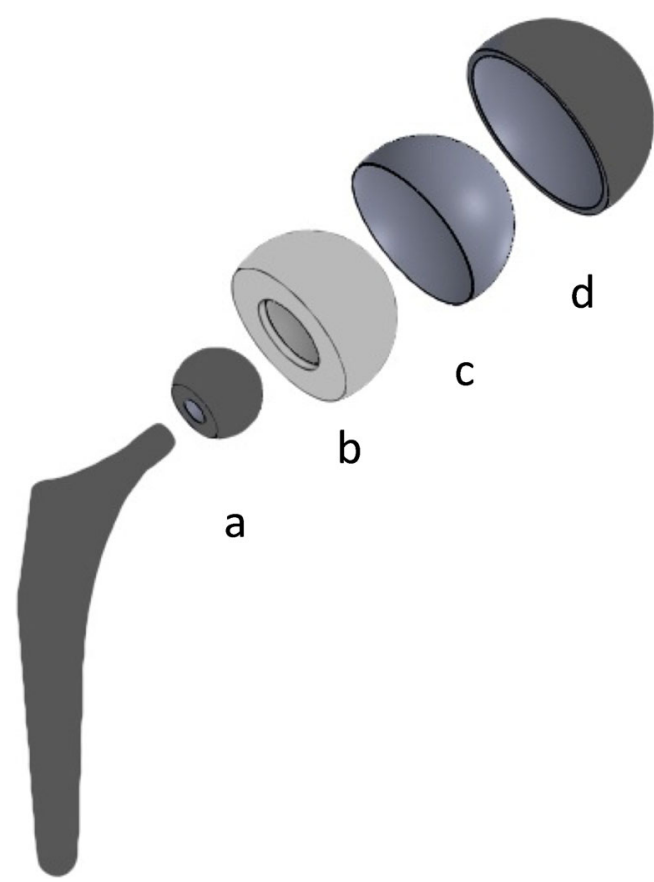

Fig. 1 Magnified view of the dual-mobility (DM) design showing interfaces involved in biological processes: a taper junction between head and stem; b small articulation between head and poly insert; $\mathbf{c}$ articulation between poly insert and metal liner; $\mathbf{d}$ engagement between convex surface of metal liner and acetabular shell. (Metal liner is a US variation of the original French design aiming at enhancing cup fixation by the presence of screw holes) "jump distance" needed to dislocate the ball from the acetabulum. The two bearings are theoretically never moving at the same time.

The DM concept, conceived and developed by Professor Gilles Bousquet and engineer Andre' Rambert in the late 1970 s with the aim of reducing wear and increasing mobility, incorporates the "low-friction" principle introduced by Charnely [19] and the McKnee-Farrar concept of large heads to enhance stability [20]. DM bearings have been extensively used in Europe as an alternative to constrained liners, together with large heads, to solve instability. However, the bearings were approved by the US Food and Drug Administration (FDA) as late as 2009. The designs currently available in Europe and the USA are reported in Table 1.

The first dual-articulation acetabular cup system (Novae Tripod, Serf, Decines, France) consisted of a cementless stainless steel acetabular shell with a porous plasma-sprayed alumina coating, fixation of which relied on two Morse taper pegs impacted into the ischium and pubis, respectively, and one $4.5-\mathrm{mm}$ screw inserted into the ilium at $45^{\circ}$ to the sagittal plane. The PE liner was $5 / 8$ of a sphere and retained a 22.2$\mathrm{mm}$ head, with the three components sharing the same centre [21]. The original cup was modified in the late 1990s by changing the shape of the metal component from cylindrical/ spherical to hemispherical [22], subhemispherical and anatomical to improve the ROM. Double-layer coating of hydroxyapatite and titanium plasma spray has been added to facilitate osseointegration on the outer surface [23]. The PE insert has been modified by adding a retentive chamber, and the femoral neck has become thinner and smoother to reduce liner impingement and the risk of wear and dislocation [24]. The evolution of design and materials used in these prostheses has led to a gain in their popularity worldwide.

\section{Biomechanical function of DM bearings}

As the PE liner expands the head diameter and articulates with the metal shell, it recreates a large-diameter femoral head, increasing the head-neck ratio. Large femoral heads not only increase the jump distance, defined as the distance the head must travel to leave the acetabulum (amounts to $50 \%$ of the head diameter in hemispherical cups; less in subhemispherical cups) [25], thus reported to be a valid option to reduce the risk of dislocation [26] and ROM before impingement [27]. ROM at the natural hip joint during normal daily activities has been reported to be wide: flexion/extension can reach up to $124^{\circ}$, abduction/adduction up to $28^{\circ}$ and internal/external rotation up to $33^{\circ}$. DM cups can add an extra $30.5^{\circ}$ in flexion, $15.4^{\circ}$ in abduction and $22.4^{\circ}$ in external rotation in comparison with conventional implants [28]. Head diameter in isolation is only a portion of the entire mechanism of hip dislocation. Implant position, patient anatomy and soft tissue tension are also 


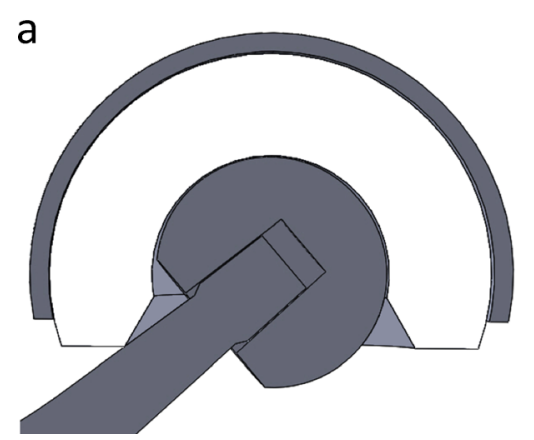

Fig. 2 Cross-sectional view of the modern dual-mobility (DM) design with the chamfered edge of the retentive polyethylene rim. a The configuration allows a greater range of motion (ROM) before impingement due

important, as use of large heads is only insufficient when a high cup abduction angle is present and even less so when there is an increased offset of the femoral head as it in turn reduces the jump distance [29]. Large femoral heads, increased modularity and a wide ROM are all variables known to possibly enhance wear at the interfaces.

\section{Wear and its clinical relevance in DM design}

Despite the availability of sophisticated methodologies to test new implants, analysis of retrieved components provides important insights into their in vivo performance [30]. Although there have been reports of wear at the surfaces involved in modular THAs, there is little data regarding such investigation in DM hips (Table 2).

Wear modes possible for DM cups are comparable with those described for standard cups; however, as the poly moves within the acetabular shell, a second poly surface is a possible source of debris. Concerns arise regarding increased frictional torque resulting in excessive wear, osteolysis and loosening

Table 1 Types of dual-mobility bearings (DM) in use in USA and Europe

\begin{tabular}{ll}
\hline Company & Design \\
\hline ASTON Medical & TREGOR Dual Mobility Acetabular System \\
Biomet & Active Articulation E1 \\
Lima & $2 \mathrm{M}$ \\
Medacta International & Versafitcup Double Mobility \\
Smith \& Nephew & Polar Cup \\
Stryker & Mobile Bearing Hip System \\
Amplitude & Saturne \\
Science and Medicine & Evora \\
Serf & Novae \\
Tornier & Dual Mobility Acetabular Cup \\
Groupe Lepine & QUATTRO \\
Wright Medical France & Collégia \\
\hline
\end{tabular}

b

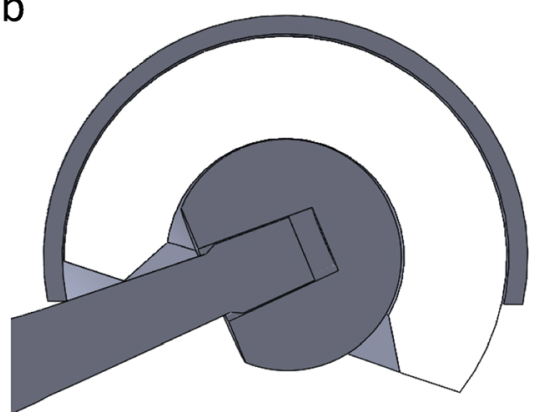

to the relative motion of the polyethylene liner into the acetabular metal cup; b standard bearings in which the polyethylene insert is fixed into the cup

for DM cups. A classification for modes of wear has been devised by McKellop [47] and includes:

Mode 1: Occurs between two bearing surfaces contacting each other and moving under load. This mode leads to wear but is necessary for the implant to function.

Mode 2: Occurs between a bearing and a nonbearing surface, e.g. when the head is dragged across the rim of the shell during dislocation. May involve severe implant wear and rapid failure.

Mode 3: Occurs when abrasive third-body particles are interposed between bearing surfaces. This mode may increase the wear rate in comparison with Mode 1.

Mode 4: Occurs between two nonbearing surfaces moving against each other under load condition, e.g. neck socket/neck poly liner impingement (Fig. 2). Debris generated may be sufficient to generate local osteolytic reactions or metallosis.

In addition, damage can occur at the taper junction due to mechanical wear mechanisms and/or precipitation of joint fluids [47].

In terms of surface damage, several types have been identified for PE-from pitting to abrasion, delamination, polishing, burnishing, scratching, gouging. However, high surface-damage score does not always link with a great amount of wear. In fact, in quantifying poly wear, the challenge is to distinguish between material lost and plastic deformation, a problem drastically minimised when considering metals and ceramics.

Impingement (or wear Mode 4) of the neck (or taper) with the liner can lead to accelerated wear and is influenced by prosthetic design, component position, biomechanical factors and patient variables. Evidence linking impingement to dislocation and accelerated wear comes from implant retrieval studies. For instance, specific patterns of wear have been described on retrieved DM components failed due to impingement. One such pattern is the presence of a notch on the stem 
Table 2 Retrieval studies investigating surface wear on dual-mobility (DM) component surfaces in comparison with standard bearings. There is no data regarding taper junction and interface acetabular cup/metal liner due to its recent introduction

Interfaces

due to the metal neck rubbing on the metal back [12] or the symmetrically placed wear pattern on the neck, indicating impingement with the retentive rim $[22,41]$. Another characteristic feature is the asymmetric wear pattern seen on the poly insert due to its varus tilting [42] or the eccentric/concentric wear configuration at the poly inner surface [34, 41], suggesting greater movement at the head-poly articulation.

A specific failure mode with DM cups is called intraprosthetic dislocation (IPD) and is defined as the excessive wear at the head-liner interface that leads to separation of the head from the liner. Changes made to cup design, use of HXLPE for the liner and use of thinner and smoother trunnions seem to have led to better results. Loosening still constitutes a concern when it comes to young patients, as wear is a function of time and use; this applies in general to all types of PE cups, explaining the trend towards hard bearings [3]. Thus, longer follow-ups for this type of patient are needed. Figure 3 shows retrieved components of a modern DM design.

Signs of PE liner wear have been reported as radiographic abnormalities; e.g. the characteristic eccentric position of the neck with respect to the head. However, this is visible after IPD has occurred and is a diagnostic indicator for surgical intervention [22, 48, 49]. When conventional dislocation occurs - in other words, when the poly liner dislodges the shell-radiographs may reveal a circular radiolucent area above the shell [50]. Although a radiostereometric method was conceived by Pineau et al. [51] to measure femoral head migration inside the cup, to our knowledge, it has not been
Fig. 3 Overview of retrieved components of a modern dualmobility (DM) cup design. The acetabular cup can be a monobloc with porous-coated surface for osseointegration or $\mathbf{b}$ modular with screw holes and thus requiring $\mathbf{c}$ a metal liner. $\mathbf{d}$ The large mobile polyethylene liner e expands the effective head diameter, which in turn articulates within the liner following movements of the stem; f head-stem joint is a Morse taper
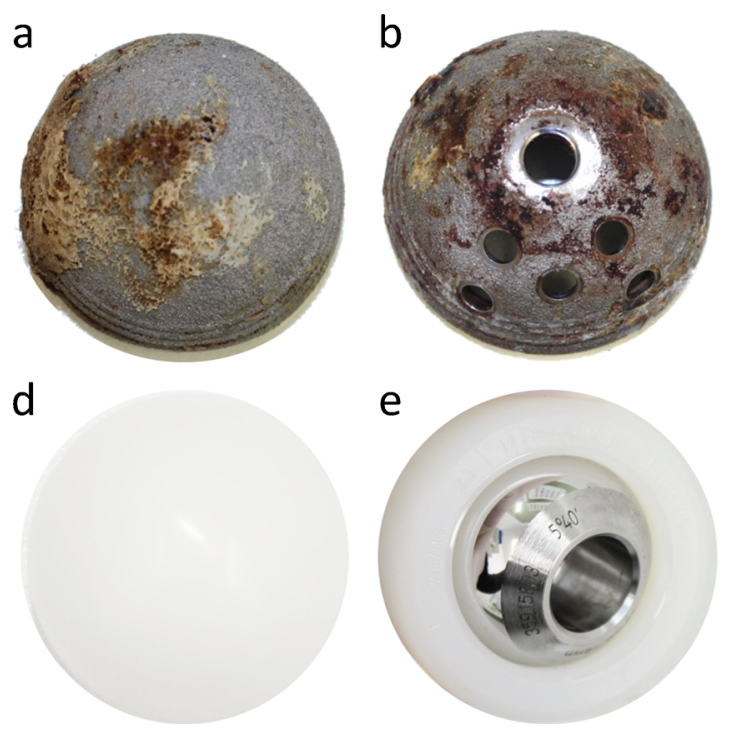
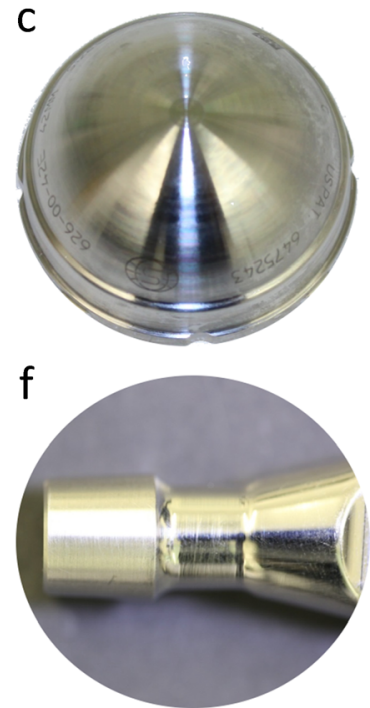
applied to measure in vivo wear. Moreover, indirect sign of poly wear is granulomatous osteolysis $[52,53]$, which is correlated with age and activity level. Vielpeau at al. [12] reported a high $(5.7 \%)$ incidence of femoral and acetabular loosening in their cohort of the original cementless DM socket, and the rate was significantly higher in young and active patients. Combes at al. [54] found a correlation between the incidence of IPD and young age, enforcing the hypothesis of a link between poly wear and dislocation.

\section{Intraprosthetic dislocation as result of $\mathrm{PE}$ wear}

Despite the advantages in terms of restored movements and improved stability associated with the use of a large-diameter femoral head, the DM design is often associated with increased risk of impingement, as head coverage by the poly liner is larger when compared with standard bearings. IPD results in head dislodgement from the PE liner and requires surgical treatment.

Three types of IPD dislocations have been described by Philippot et al. [7] and, more recently, by Fabry [55], having in common the finding of wear and deformation of the retentive rim of the intermediate components. Type 1 was described as pure IPD without arthrofibrosis and without cup loosening, type 2 was secondary to blocking of the liner and type 3 was associated with a cup loosening, with mean onset times being 11, eight and nineyears after THA, respectively. IPD is related to DM design, and different possible reasons have been linked to it. Firstly, the relative position of the head and liner can be either concentric or eccentric: Concentricity can cause the intermediate component to tilt into varus [56, 57]. In the eccentric configuration, the centre of rotation of the poly liner has a definite offset to the centre of the head, which avoids tilting into varus by realignment under loading. As the poly liner has an offset to the centre of the head, eccentricity can be lateral [22] or medial [55], with the latter showing better results. Fabry et al. [58] tested concentric and eccentric configurations with the aid of an industrial robot to simulate physiological load conditions in a lubricated environment. Results showed that in the concentric system, even after a short period of loading, the poly insert was tilted into a varus position and was independent of the direction of the applied force but was influenced by stem movements; the eccentric design showed self-realignment into an antivarus position under different loadings. As there are no reference landmarks on the poly, its tilting cannot be identified on plain radiographs and over time. Continuous impingement with the neck can cause an irreversible degree of uneven wear, decreasing the retentive power of the liner and ultimately leading to IPD. Moreover, contact between the neck and shell as well as head and shell can lead to metallosis with soft tissue damage [59].

Another important design feature is the shape of the acetabular cup: hemispherical in the first-generation design, subhemispherical latter. In 2001, anterior overhang was reduced, and press-fit was enhanced with the addition of hydroxyapatite on the outer surface. Shallow cups in combination with eccentric configuration have been suggested to increase ROM whilst decreasing the risk of impingement and thus loss of integrity of the retentive poly $[55,58]$. Moreover, insufficient clearance between acetabular shell and poly liner has been associated with intra-articular fibrosis, resulting in the blockage of outer articulation [7].

IPD incidence or retentive failure $(\mathrm{RF})$ ranging from 1.9 to $5.2 \%$ is reported with older-generation DM designs at a mean follow-up of four to 17 years [8, 21, 52, 53], with the oldergeneration design at a mean follow-up of four to 17 years and $0-2.4 \%$ at seven years with the newer-generations design [12, $22,54]$ (Table 3). Rates appear to be dependent not only on cup design but also neck design. Large-diameter heads reduce the head-to-neck ratio, increasing the risk of impingement and resulting in wear of the entire poly rim; lower RF rates were noted for the thinner Charnley neck versus the bigger PF or PRO neck. In addition, it is important to note that the Morse taper is fully engaged with the head to avoid rim fatigue [22, 55]. Recent articles have shown IPD for new DM designs in both short- and long-term series [41, 62-64], leading to implant failure. Interestingly, in these cases, the necks used were and generally of a large diameter. Thus, attention should be paid in choosing the acetabular and femoral components.

\section{Polyethylene wear assessment}

There have been several attempts at measuring the volumetric wear from the inner and outer surfaces of PE components, as there is no standardised method of quantifying it either in or ex vivo. Qualitative assessment is biased by the difficulty in differentiating the worn and unworn areas as well as between genuine wear patterns and explantation of damage at the time of revision. Quantitative evaluation is also problematic in that comparison with a pristine component of the same size and shape is not always possible and due to the difficulty in distinguishing creep from wear. Moreover, fluid impregnation for gravimetric evaluation brings inaccuracy when assessing retrievals.

\section{Radiographic analysis}

Radiological evaluation examining head penetration into the poly insert by measuring the distance between the projected neck axis and the head centre is imprecise. The head is poorly visible and its position dictated by wear of both inner and outer poly liners, which is not detectable on X-ray films [65]. Dumbleton et al. [66] observed that osteolysis was relatively uncommon when linear wear rates were $<0.1 \mathrm{~mm} /$ year. Lautridou et al. [61] applied this assessment method to 44 hips with follow-up of $>15$ years. Linear wear was at least $3 \mathrm{~mm}$ 
Table 3 Intraprosthetic dislocation (IPD) rate at long-term follow-up (FU) in dual-mobility (DM) acetabular cups

\begin{tabular}{|c|c|c|c|c|c|}
\hline Reference & CNo. hips & Average FU (years) & Cup design & Stem design & $\operatorname{IPD}(\%)$ \\
\hline Philippot at al, 2006 [52] & 106 & 10 & Novae- $1^{\mathrm{a}}$ & Profil- $^{\mathrm{a}}$ & 1.9 \\
\hline Philippot et al., 2009 [21] & 384 & 15.3 & Novae- $1^{\mathrm{a}}$ & $160 \mathrm{PF}^{\mathrm{a}}, 224 \mathrm{PRO}^{\mathrm{a}}$ & 3.6 \\
\hline Philippot et al., 2008 [60] & 438 & 17 & Novae- $1^{\mathrm{a}}$ & $185 \mathrm{PF}^{\mathrm{a}}, 228 \mathrm{PRO}^{\mathrm{a}}, 25$ Corail $^{\mathrm{b}}$ & 5.2 \\
\hline Boyer et al., 2012 [8] & 240 & 22 & Novae $^{a}$ & $\mathrm{PF}^{\mathrm{a}}$ & 4.1 \\
\hline Farizon et al., 1998 [53] & 135 & 12 & Novae $^{a}$ & $\mathrm{PIM} / \mathrm{PF}^{\mathrm{a}}$ & 2 \\
\hline Lautridou et al., 2008 [61] & 437 & 16.5 & Novae- $1^{\text {a }}$ & Charnley & 0.7 \\
\hline Vielpeau et al., 2011 [12] & $\begin{array}{l}437 \\
668 \\
231\end{array}$ & $\begin{array}{l}16.5 \\
5.2\end{array}$ & $\begin{array}{l}\text { Original Bousquet } \\
\text { Novae- } \mathrm{E}^{\mathrm{a}}\end{array}$ & $\begin{array}{l}\text { Charnley } \\
\text { Dedicace }^{\mathrm{c}}\end{array}$ & $\begin{array}{l}0.7 \\
0\end{array}$ \\
\hline Combes et al., 2013 [54] & 2480 & 7 & Multiple designs & NA & 0.28 \\
\hline Hamadouche et al., 2012 [22] & 168 & 6 & Tregor $^{\mathrm{d}}$ & Respect $^{\mathrm{d}}$ & 2.4 \\
\hline
\end{tabular}

NA not available

${ }^{a}$ Serf, Décines, France

${ }^{\mathrm{b}}$ DePuy, Warsaw, IN, USA

${ }^{\mathrm{c}}$ Stryker, Pusignan, France

${ }^{\mathrm{d}}$ Aston, St Etienne, France

for 13 hips. Neri et al. [67] analysed 30 ultra-high-molecularweight PE (UHMWPE) inserts with 15 years of implantation removed due to aseptic loosening. For each implant, the latest $\mathrm{X}$-rays taken prior to implant removal were examined and compared with a surface scanner measurement method to estimate internal and external surfaces of the inserts. The authors found no significant correlation between linear head penetration into the cup and global wear of the insert (values not reported), concluding that $3 \mathrm{D}$ wear of the insert as well as its random position during radiographic assessment, may be a reason. The authors concluded that with $3 \mathrm{D}$ imaging techniques, shifting of the head centre should allow estimation of global wear on the insert; however, to date, there is no evidence of such a link. Radiographic techniques do not account for pre-existing clearance between components in DM design, which varies between manufacturers [68], and it cannot discern between wear and creep, thus creating limited accuracy.

\section{Visual and 3-D surface analysis}

Visual and 3D assessments on poly retrieved components estimate that wear on the retentive rim of poly liners due to impingement $[20,35]$ is challenging but seems to be related to IPD and loosening more so than articular surface wear [69]. D'Apuzzo et al. [34] found damage on both bearings, with the inner HXLPE surface showing higher concentric wear patterns and lower prevalence of remaining machining lines and higher occurrence of embedded metal particles compared with the outer surface. Adam et al. [32] analysed 40 UHMWPE cups removed after septic or mechanical failure. The mean interval between implantation and retrieval was eight years (range 3-15.5). Surface analysis was performed comparing changes in internal and external liner sphericity with data from pristine inserts. Internal concavity was measured using a 4-mm stylus, whilst external convexity was measured by lateral projection. Total annual volumetric wear was $54 \pm 40 \mathrm{~mm}^{3} /$ year $\left(29 \pm 28 \mathrm{~mm}^{3} /\right.$ year on the convex and $26 \pm 23 \mathrm{~mm}^{3} /$ year for the concave surface). Wear of the retentive chamber was found in $40 \%$ of cases. Although most movement takes place at the small articulation, and although resulting wear rates for both articulations were similar, it may be that volumetric wear per cycle is greater in unconstrained articulation compared with articulation between head and liner. This may be due to a larger-diameter surface or because the measurement probe cannot reach the upper border of the inner poly, thus leaving behind data regarding the retentive rim. Similar wear values were estimated by Geringer et al. [33], who analyzed 12 UHMWPE components of the same hip design using a coordinate measurement machine (CMM) with a 1-mm probe. Annual wear was $36.7 \pm 29.1 \mathrm{~mm}^{3} /$ year for the convex side, $22.1 \pm 39.2 \mathrm{~mm}^{3} /$ year for the concave side and estimated total annual wear was $53.9 \pm 50.30 \mathrm{~mm}^{3} /$ year. Moreover, when arthrofibrosis was present, the second mobility was preferentially triggered, so that the convex side of the poly liner polished during movement. Significant wear-rate changes were not observed in cases of arthrofibrosis compared with those in whom it was absent. Leclercq et al. [11] assessed poly wear with 3D CT on one retrieved UHMWPE component nine years post-operatively. Linear wear was reported as $0.17 \mathrm{~mm} /$ year on the convex surface. In the 1996, Kobayashi et al. [70] reported for the first time the amount of wear created by the impingement. The surface was measured with a CMM and compared with that of an unworn cup of the same size. 
Volumetric wear related to the articulate surface was $2.3 \mathrm{~mm}^{3}$ and from the rim was $159.0 \mathrm{~mm}^{3}$. Their study involved a bipolar prosthesis, which differs from a DM type in the fact that in the latter, the poly liner is unconstrained; however, to our knowledge, this is the only attempt made at estimating wear rates from the retentive rim of the poly liner.

Several methods are used to asses wear in standard cups, ranging from stereophotogrammetric analysis (RSA) to metrology to 3D optical to 3D-CT. Conversely, the amount of data available on DM bearings is notably greater due to their longer time on the market and their massive worldwide use.

\section{Simulation}

To overcome or minimize wear, HXLPE liners have been introduced and registry data show the rapid increase in their use [3-5]. Wear rates of such implants appear to be lower than previously reported for standard PE liners [17]. The long-term survival rates of highly cross-linked PE have not been fully established; however, short-term studies show a 45-95\% reduction in wear at three to five years [71, 72]. Moreover, wear data on retrieved HXLPE cups are unavailable for DM prosthesis except for one based on qualitative assessment [34].

\section{UHMWPE}

The majority of simulation studies regarding PE wear in DM cups tested HXLPE. To our knowledge, only Saikko et al. [73] evaluated wear of UHMWPE inserts. The authors compared DM design with a typical modular design in a hip-joint simulator at 5 million cycles at both $45^{\circ}$ and $60^{\circ}$ cup abduction. Mean wear rates were comparable between the two designs, and increasing acetabular shell abduction did not result in a significant change in wear rate.

\section{HXLPE}

Loving et al. [13] measured wear of HXLPE inserts in a hip simulator under the aggressive conditions of immobilised liner, impingement and abrasion. Wear rates were smaller than those with single articulation for each testing condition. In another study, [14] the same authors examined the influence of cup inclination $\left(50^{\circ}\right.$ and $\left.65^{\circ}\right)$ on wear behavior of the HXLPE bearing surface. The authors found that steep cup inclination had no influence on poly wear in DM cups, exhibiting even better results compared with standard metalon-PE bearings. Netter et al. [74] monitored the wear behavior of DM prosthesis in the presence of microseparation and thirdbody particles. Microseparation increased wear rates; however, values were low and under the level reported to be of clinical relevance. No measurable increase in poly wear was linked with third-body-particle test conditions.
To date simulation studies have shown reasonable wear performance of HXLPE in DM component design; however, as with all simulation studies, they all have limitations and cannot reproduce the full kinematic conditions occurring in vivo.

\section{Conclusions}

Our critical review of the literature of DM bearings has created a rational classification for sites of wear, highlighted gaps in the literature concerning long-term in vivo wear performance for future research and helped summarise current evidence so that surgeons can better understand the risk/benefit balance of using evidencebased medicine.

The evolution of DM design and materials has led to an increased popularity worldwide. Reported results indicate their efficacy at reducing dislocation and a recommendation that they should be considered for patients with risk factors for complication such as neurological disease, hip abductor muscle destruction and revision surgery. As for standard cups, concerns over wear arise when considering young and active patients; with little published in the literature thus far, this is an important factor to be considered when selecting a bearing type for each patient.

Wear performance of such devices needs long-term followup for newer designs. Wear of first-generation designs was high and possibly related to design features and materials, often resulting in IPD [15, 39, 55]. Improved PE fabrication - besides the adoption of thinner and smoother trunnions, chamfered rims and eccentric centres of insert and shell rotation-have reduced this problem over the short $[7,8]$ and medium $[34,45,46]$ terms. Recent articles describe early failure of new DM designs in both short- and long-term series [41, 62-64]. Notably in these cases, necks used were and generally of a large diameter. Thus, the choice of acetabular and femoral components from different device manufacturers seems to play a role in outcome performance of cups. There is need for long-term clinical evidence and retrieval studies to better understand which patients will benefit most from this exciting technology.

\section{Compliance with ethical standards}

Conflict of interest The authors declare that they have no conflict of interest.

Funding There is no funding source.

Ethical approval This article does not contain any studies with human participants or animals performed by any of the authors. 
Open Access This article is distributed under the terms of the Creative Commons Attribution 4.0 International License (http:// creativecommons.org/licenses/by/4.0/), which permits unrestricted use, distribution, and reproduction in any medium, provided you give appropriate credit to the original author(s) and the source, provide a link to the Creative Commons license, and indicate if changes were made.

\section{References}

1. Woo RY, Morrey BF (1982) Dislocations after total hip arthroplasty. J Bone Joint Surg Am 64(9):1295-1306

2. Berry DJ, von Knoch M, Schleck CD, Harmsen WS (2004) The cumulative long-term risk of dislocation after primary Charnley total hip arthroplasty. J Bone Joint Surg Am 86(1):9-14

3. Swedish Hip Arthroplasty Register (2014) Annual report

4. National Joint Registry for England, Wales and Northern Ireland (2013) 10th annual report

5. Australian Orthopaedic Association (2015) National joint replacement registry annual report

6. Sanchez-Sotelo J, Haidukewych GJ, Boberg CJ (2006) Hospital cost of dislocation after primary total hip arthroplasty. J Bone Joint Surg Am 88(2):290-294

7. Philippot R, Boyer B, Farizon F (2013) Intraprosthetic dislocation: a specific complication of the dual-mobility system. Clin Orthop Relat Res 471(3):965-970

8. Boyer B, Philippot R, Geringer J, Farizon F (2012) Primary total hip arthroplasty with dual mobility socket to prevent dislocation: a 22-year follow-up of 240 hips. Int Orthop 36(3):511-518

9. Caton JH, Prudhon JL, Ferreira A, Aslanian T, Verdier R (2014) A comparative and retrospective study of three hundred and twenty primary Charnley type hip replacements with a minimum follow up of ten years to assess wether a dual mobility cup has a decreased dislocation risk. Int Orthop 38(6):1125-1129

10. Prudhon J-L, Ferreira A, Verdier R (2013) Dual mobility cup: dislocation rate and survivorship at ten years of follow-up. Int Orthop 37(12):2345-2350

11. Leclercq S, Benoit J, De Rosa J, Tallier E, Leteurtre C, Girardin P (2013) Evora ${ }^{\circledR}$ chromium-cobalt dual mobility socket: results at a minimum 10-years' follow-up. Orthop Traumatol Surg Res 99(8): 923-928

12. Vielpeau C, Lebel B, Ardouin L, Burdin G, Lautridou C (2011) The dual mobility socket concept: experience with 668 cases. Int Orthop 35(2):225-230

13. Loving L, Lee RK, Herrera L, Essner AP, Nevelos JE (2013) Wear performance evaluation of a contemporary dual mobility hip bearing using multiple hip simulator testing conditions. J Arthroplast 28(6):1041-1046

14. Loving L, Herrera L, Banerjee S, Heffernan C, Nevelos J, Markel DC, Mont MA (2015) Dual mobility bearings withstand loading from steeper cup-inclinations without substantial wear. J Orthop Res 33(3):398-404

15. Page has been provided please check if correct.->Vigdorchik JM, D'Apuzzo MR, Markel DC, Malkani AL, Raterman S, Sharpe KP, Cornell CN, Westrich GH (2015) Lack of early dislocation following total hip arthroplasty with a new dual mobility acetabular design. Hip Int 25(1):34-38

16. Epinette J-A (2015) Clinical outcomes, survivorship and adverse events with mobile-bearings versus fixed-bearings in hip arthroplasty-A prospective comparative cohort study of 143 ADM versus 130 trident cups at 2 to 6 -year follow-Up. J Arthroplast 30(2):241-248

17. Paxton EW, Inacio MC, Namba RS, Love R, Kurtz SM (2015) Metal-on-conventional polyethylene total hip arthroplasty bearing surfaces have a higher risk of revision than metal-on-highly crosslinked polyethylene: results from a US registry. Clin Orthop Relat Res 473(3):1011-1021

18. Fessy M, (2006) Dual mobility: a stephanois concept. Maîtrise Orthopédique, 152

19. Charnley J (1972) The long-term results of low-friction arthroplasty of the hip performed as a primary intervention. Bone Joint J 54(1): 61-76

20. McKee G, Watson-Farrar J (1966) Replacement of arthritic hips by the McKee-Farrar prosthesis. Bone Joint J 48(2):245-259

21. Philippot R, Camilleri JP, Boyer B, Adam P, Farizon F (2009) The use of a dual-articulation acetabular cup system to prevent dislocation after primary total hip arthroplasty: analysis of 384 cases at a mean follow-up of 15 years. Int Orthop 33(4):927-932

22. Hamadouche M, Arnould H, Bouxin B (2012) Is a cementless dual mobility socket in primary THA a reasonable option? Clin Orthop Relat Res 470(11):3048-3053

23. Massin P, Orain V, Philippot R, Farizon F, Fessy MH (2012) Fixation failures of dual mobility cups: a mid-term study of 2601 hip replacements. Clin Orthop Relat Res 470(7):1932-1940

24. Guyen O, Pibarot V, Vaz G, Chevillotte C, Béjui-Hugues J (2009) Use of a dual mobility socket to manage total hip arthroplasty instability. Clin Orthop Relat Res 467(2):465-472

25. Morlock MM, Bishop N, Huber G, (2011) Biomechanics of hip arthroplasty. Tribology in Total Hip Arthroplasty: Springer, p. 1124

26. Amstutz HC, Le Duff MJ, Beaulé PE (2004) Prevention and treatment of dislocation after total hip replacement using large diameter balls. Clin Orthop Relat Res 429:108-116

27. Crowninshield RD, Maloney WJ, Wentz DH, Humphrey SM, Blanchard CR (2004) Biomechanics of large femoral heads: what they do and don't do. Clin Orthop Relat Res 429:102-107

28. Guyen O, Chen QS, Bejui-Hugues J, Berry DJ, An K-N (2007) Unconstrained tripolar hip implants: effect on hip stability. Clin Orthop Relat Res 455:202-208

29. Sariali E, Lazennec JY, Khiami F, Catonné Y (2009) Mathematical evaluation of jumping distance in total hip arthroplasty: influence of abduction angle, femoral head offset, and head diameter. Acta Orthop 80(3):277-282

30. Jacobs JJ, Wimmer MA (2013) An important contribution to our understanding of the performance of the current generation of metal-on-metal hip replacements. J Bone Joint Surg Am 95(8):e53

31. Hothi HS, Ilo K, Whittaker RK, Eskelinen A, Skinner JA, Hart AJ (2015) Corrosion of metal modular cup liners. J Arthroplast 30(9): 1652-1656

32. Adam P, Philippe R, Ehlinger M, Roche O, Bonnomet F, Molé D, Fessy MH (2012) Dual mobility cups hip arthroplasty as a treatment for displaced fracture of the femoral neck in the elderly. A prospective, systematic, multicenter study with specific focus on postoperative dislocation. Orthop Traumatol Surg Res 98(3):296-300

33. Geringer J, Boyer B, Farizon F (2011) Understanding the dual mobility concept for total hip arthroplasty. Investigations on a multiscale analysis-highlighting the role of arthrofibrosis. Wear 271(9):2379-2385

34. D'Apuzzo MR, Koch CN, Esposito CI, Elpers ME, Wright TM, Westrich GH (2016) Assessment of damage on a dual mobility acetabular system., The Journal of Arthroplasty

35. Salineros MJ, Crowninshield RD, Laurent M, Wimmer MA, Jacobs JJ (2007) Analysis of retrieved acetabular components of three polyethylene types. Clin Orthop Relat Res 465:140-149

36. Hall RM, Unsworth A, Siney P, Wroblewski BM (1996) Wear in retrieved Charnley acetabular sockets. Proc Inst Mech Eng H J Eng Med 210(3):197-207

37. Jasty M, Goetz DD, Bragdon CR, Lee KR, Hanson AE, Elder JR, Harris WH (1997) Wear of polyethylene acetabular components in total hip arthroplasty. An analysis of one hundred and twenty-eight 
components retrieved at autopsy or revision operations. J Bone Joint Surg Am 79(3):349-358

38. Hothi HS, Berber R, Whittaker RK, Blunn GW, Skinner JA, Hart $\mathrm{AJ}$ (2016) The relationship between cobalt/chromium ratios and the high prevalence of head-stem junction corrosion in metal-on-metal total hip arthroplasty. J Arthroplast 31(5):1123-1127

39. Matthies AK, Racasan R, Bills P, Blunt L, Cro S, Panagiotidou A, Blunn G, Skinner J, Hart AJ (2013) Material loss at the taper junction of retrieved large head metal-on-metal total hip replacements. J Orthop Res 31(11):1677-1685

40. Cook RB, Bolland BJ, Wharton JA, Tilley S, Latham JM, Wood RJ (2013) Pseudotumour formation due to tribocorrosion at the taper interface of large diameter metal on polymer modular total hip replacements. J Arthroplast 28(8):1430-1436

41. Odland AN, Sierra RJ (2014) Intraprosthetic dislocation of a contemporary dual-mobility design used during conversion THA. Orthopedics 37(12):e1124-e1128

42. Langlais FL, Ropars M, Gaucher F, Musset T, Chaix O (2008) Dual mobility cemented cups have low dislocation rates in THA revisions. Clin Orthop Relat Res 466(2):389-395

43. Hall RM, Siney P, Unsworth A, Wroblewski BM (1998) Prevalence of impingement in explanted Charnley acetabular components. J Orthop Sci 3:204-208

44. Shon WY, Baldini T, Peterson MG, Wright TM, Salvati EA (2005) Impingement in total hip arthroplasty: a study of retrieved acetabular components. J Arthroplasty 20:427-435

45. Usrey MM, Noble PC, Rudner LJ, Conditt MA, Birman MV, Santore RF, Mathis KB (2006) Does neck/liner impingement increase wear of ultrahigh-molecular-weight polyethylene liners? J Arthroplasty 21(6 Suppl 2):65-71

46. Yamaguchi M, Akisue T, Bauer TW, Hashimoto Y (2000) The spatial location of impingement in total hip arthroplasty. J Arthroplasty 15:305-313

47. McKellop HA (2007) The lexicon of polyethylene wear in artificial joints. Biomaterials 28(34):5049-5057

48. Langlois J, El Hage S, Hamadouche M (2014) Intraprosthetic dislocation: a potentially serious complication of dual mobility acetabular cups. Skelet Radiol 43(7):1013-1016

49. Banka TR, Ast MP, Parks ML (2014) Early intraprosthetic dislocation in a revision dual-mobility hip prosthesis. Orthopedics 37(4): e395-e397

50. De Martino I, Triantafyllopoulos GK, Sculco PK, Sculco TP (2014) Dual mobility cups in total hip arthroplasty. World J Orthop 5(3): 180

51. Pineau V, Lebel B, Gouzy S, Dutheil J-J, Vielpeau C (2010) Dual mobility hip arthroplasty wear measurement: experimental accuracy assessment using radiostereometric analysis (RSA). Orthop Traumatol Surg Res 96(6):609-615

52. Fabry, C., Langlois, J., Hamadouche, M., \& Bader, R (2016) Intraprosthetic dislocation of dual-mobility cups after total hip arthroplasty: potential causes from a clinical and biomechanical perspective. Int Orthop, 1-6

53. Muratoglu OK, Bragdon CR, O'Connor D, Perinchief RS, Estok DM, Jasty M, Harris WH (2001) Larger diameter femoral heads used in conjunction with a highly cross-linked ultra-high molecular weight polyethylene: a new concept. J Arthroplast 16(8):24-30

54. Lecuire F, Benareau I, Rubini J, Basso M (2004) Intra-prosthetic dislocation of the Bousquet dual mobility socket. Rev Chir Orthop Reparatrice Appar Mot 90(3):249-255

55. Fabry C, Kaehler M, Herrmann S, Woernle C, Bader R (2014) Dynamic behavior of tripolar hip endoprostheses under physiological conditions and their effect on stability. Med Eng Phys 36(1): $65-71$
56. Mohammed R, Cnudde P (2012) Severe metallosis owing to intraprosthetic dislocation in a failed dual-mobility cup primary total hip arthroplasty. J Arthroplast 27(3):493, e1-e3

57. Philippot R, Adam P, Farizon F, Fessy M-H, Bousquet G, (2006) Survival of cementless dual mobility sockets: 10-year follow-up

58. Philippot R, Farizon F, Camilleri JP, Boyer B, Derhi G, Bonnan J, Lecuire F (2008) Survival of dual mobility socket with a mean 17 years follow-up. Rev Chir Orthop Reparatrice Appar Mot 94(1): 43-48

59. Farizon F, De Lavison R, Azoulai J, Bousquet G (1998) Results with a cementless alumina-coated cup with dual mobility. Int Orthop 22(4):219-224

60. Lautridou C, Lebel B, Burdin G, Vielpeau C (2008) Survival of the cementless Bousquet dual mobility cup: minimum 15-year followup of 437 total hip arthroplasties. Rev Chir Orthop Reparatrice Appar Mot 94(8):731-739

61. Combes A, Migaud H, Girard J, Duhamel A, Fessy MH (2013) Low rate of dislocation of dual-mobility cups in primary total hip arthroplasty. Clin Orthop Relat Res 471(12):3891-3900

62. Banzhof JA, Robbins CE, van der Ven A, Talmo CT, Bono JV (2013) Femoral head dislodgement complicating use of a dual mobility prosthesis for recurrent instability. J Arthroplast 28(3):543-e1

63. Schirmers J, Horazdovsky R, Marston S, (2014) Early intraprosthetic dislocation of dual-mobility total hip arthroplasty implant following attempted closed reduction: a case report. Reconstr Rev, 5(2)

64. Ward JP, McCardel BR, Hallstrom BR (2013) Complete dissociation of the polyethylene component in a newly available dual-mobility bearing used in total hip arthroplasty. JBJS Case Connect 3(3):e94

65. Grazioli A, Ek ETH, Rüdiger HA (2012) Biomechanical concept and clinical outcome of dual mobility cups. Int Orthop 36(12): 2411-2418

66. Dumbleton JH, Manley MT, Edidin AA (2002) A literature review of the association between wear rate and osteolysis in total hip arthroplasty. J Arthroplast 17(5):649-661

67. Neri T, Boyer B, Geringer J, Philippot R, Farizon F (2015) Intérêt de l'analyse radiologique dans l'usure des prothèses de hanche double mobilité-apport de l'analyse d'explants. Rev Chir Orthop Traumatol 101(7):S185-S186

68. Saffarini M, Gregory T, Vandenbussche E, (2016) Quantification of clearance and creep in acetabular wear measurements. Ann Translat Med, 4(7)

69. Messieh M, Mattingly DA, Turner RH, Scott R, Fox J, Slater J (1994) Wear debris from bipolar femoral neck-cup impingement: a cause of femoral stem loosening. J Arthroplast 9(1):89-93

70. Kobayashi S, Takaoka K, Tsukada A, Ueno M (1998) Polyethylene wear from femoral bipolar neck-cup impingement as a cause of femoral prosthetic loosening. Arch Orthop Trauma Surg 117(67):390-391

71. Jameson SS, Lees D, James P, Serrano-Pedraza I, Partington PF, Muller SD, Meek RM, Reed MR (2011) Lower rates of dislocation with increased femoral head size after primary total hip replacement. J Bone Joint Surg (Br) 93(7):876-880

72. Digas G, Kärrholm J, Thanner J, Herberts P (2007) 5-year experience of highly cross-linked polyethylene in cemented and uncemented sockets: two randomized studies using radiostereometric analysis. Acta Orthop 78(6):746-754

73. Saikko V, Shen M (2010) Wear comparison between a dual mobility total hip prosthesis and a typical modular design using a hip joint simulator. Wear 268(3):617-621

74. Netter JD, Hermida JC, Chen PC, Nevelos JE, D'Lima DD (2014) Effect of microseparation and third-body particles on dual-mobility crosslinked hip liner wear. J Arthroplast 29(9):1849-1853 